\title{
Increased expression of placenta growth factor in COPD
}

\author{
S-L Cheng, ${ }^{1,2}$ H-C Wang, ${ }^{2}$ C-J Yu, ${ }^{2}$ P-C Yang ${ }^{2}$
}

${ }^{1}$ Department of Internal Medicine, Far Eastern Memorial Hospital, Taiwan, ROC;

${ }^{2}$ Department of Internal Medicine, National Taiwan University Hospital, Taiwan, ROC

Correspondence to:

Dr C-J Yu, Department of Internal Medicine, National Taiwan University Hospital, No.

7. Chung-Shan South Road, Taipei, Taiwan; jefferycjyu@ntu. edu.tw

Received 11 July 2007 Accepted 21 November 2007

Published Online First

17 January 2008

\author{
ABSTRACT \\ Background: Vascular endothelial growth factor (VEGF) \\ and its receptor may have an important role in the \\ pathogenesis of emphysema. The effect of another \\ angiogenic factor, placenta growth factor (PIGF), in \\ chronic obstructive pulmonary disease (COPD) is \\ unknown.
}

Methods: The serum levels of VEGF and PIGF in patients with COPD $(n=184)$, smokers $(n=212)$ and nonsmokers $(n=159)$ and the bronchoalveolar lavage (BAL) fluid levels of VEGF and PIGF in another group (20 patients with COPD, 18 controls) were measured. In vitro cell culture experiments were performed to investigate the effect of PIGF on VEGF.

Results: The mean (SE) serum levels of PIGF were significantly higher in patients with COPD than in controls (27.1 (7.4) pg/ml vs 12.3 (5.1) pg/ml in smokers and 10.8 (6.3) $\mathrm{pg} / \mathrm{ml}$ in non-smokers, $p=0.005$ ). The levels of PIGF in BAL fluid were also significantly higher in patients with COPD than in controls (45.7 (12.3) pg/ml vs 23.9 (7.6) $\mathrm{pg} / \mathrm{ml}, \mathrm{p}=0.005)$, associated with an increase in the cytokines tumour necrosis factor- $\alpha$ (TNF- $\alpha$ ) and interleukin-8 (IL-8). In patients with COPD the levels of PIGF correlated inversely with forced expiratory volume in $1 \mathrm{~s}\left(\mathrm{FEV}_{1}\right)$ in serum $(r=-0.59, p=0.002)$ and in BAL fluid $(r=-0.51, p=0.001)$. While the serum levels of VEGF were the same in patients with COPD and controls, the BAL fluid levels were significantly lower in patients with COPD than in controls (127.5 (30.1) pg/ml vs 237.8 (36.1) $\mathrm{pg} / \mathrm{ml}, \mathrm{p}=0.002$ ). In cultured bronchial epithelial cells, proinflammatory cytokines induced an increase in the protein expression of both PIGF and VEGF. Continuous concomitant treatment with PIGF, TNF- $\alpha$ and IL-8 stimulation reduced VEGF expression and induced cell death. This phenomenon was suppressed by VEGF receptor inhibitor (CBO-P11).

Conclusions: The serum and BAL fluid levels of PIGF are increased in patients with COPD and are inversely correlated with FEV 1 . Concomitant treatment with PIGF, TNF- $\alpha$ and IL- 8 causes detrimental effects on airway epithelial cells. These data suggest that bronchial epithelial cells can express PIGF, which may contribute to the pathogenesis of COPD.

The pathogenesis of chronic obstructive pulmonary disease (COPD) is hypothesised to result from an imbalance of proteases and antiproteases in the lung. ${ }^{1}$ The theory proposes that increased numbers of neutrophils and macrophages, activated by cigarette smoke, produce proteases and oxidants that are responsible for the destruction of pulmonary tissues. ${ }^{2}$ However, in 1959, based on histological examinations of lung tissues from patients with pulmonary emphysema, Liebow noticed that the alveolar septa in centrilobular emphysema appear to be remarkably thin and almost avascular. ${ }^{3} \mathrm{He}$ suggested that a reduction in the blood supply of the small precapillary blood vessels might induce the disappearance of alveolar septa. This "vascular hypothesis" of COPD has been supported by the results of a recent study in which the expression of both vascular endothelial growth factor (VEGF) and its receptor were shown to be decreased in lung tissue from patients with COPD. ${ }^{4}$ Besides, cigarette smoke disrupts components of VEGF 165 and its receptor VEGFR2 with decreased expression of VEGF and its receptors in the lungs of rats and humans. ${ }^{5}$ The pathogenesis of COPD may therefore be more complex and multifactorial, resulting from an interaction between genetic, environmental, cigarette smoke and angiogenesis factors.

Little is known about another angiogenic growth factor called placenta growth factor (PIGF). PIGF is a $50 \mathrm{kDa}$ glycosylated dimeric protein which shares significant sequence homology at the amino acid level with VEGF. ${ }^{6}$ Like VEGF, PIGF exhibits mitogenic activity on cultured endothelial cells and induces angiogenesis in vivo, and its effects on endothelial cells are similar to those of the potent classical angiogenic factors such as VEGF and fibroblast growth factor. ${ }^{7}$ Receptors for VEGF, the fms-like tyrosine kinase receptor (flt-1, VEGFR1) and the kinase insert domain-containing receptor (KDR, VEGFR2) are homodimeric, receptor tyrosine kinase. While VEGF binds with high affinity to both flt-1 and KDR, PIGF exhibits high affinity binding only to flt-1. ${ }^{8}$ Normally, PIGF mRNA is present most abundantly in the placenta, thyroid and lungs, ${ }^{9}$ but the biological function of PIGF in these tissues remains unclear. A previous study has shown significantly enlarged air spaces and enhanced pulmonary compliance-a situation mimicking human pulmonary emphysema-in PIGF transgenic mice. ${ }^{10}$ It was the first study to suggest an association between PIGF and pulmonary emphysema in mice, but whether it can be shown in humans is unknown.

A study was undertaken to elucidate the role of VEGF and PIGF in patients with COPD. We first measured the levels of VEGF and PIGF in serum and bronchoalveolar lavage (BAL) fluid from patients with COPD. We then studied the regulation of PIGF and VEGF in cultured bronchial epithelial cells after exposure to various pro-inflammatory cytokines, as well as the effects of 14 days exposure to heightened PIGF on bronchial epithelial cells.

\section{METHODS}

\section{Subjects}

\section{Study population 1}

Study population 1 consisted of 184 patients (152 men and 32 women) with smoking-related COPD. online under the BMJ Journals unlocked scheme, see http:// thorax.bmi.com/info/unlocked.dtl 
Table 1 Age, sex, smoking and pulmonary function data in patients with COPD and controls (study population 1)

\begin{tabular}{lccc}
\hline Variables & $\begin{array}{l}\text { COPD } \\
(\mathbf{n}=\mathbf{1 8 4})\end{array}$ & $\begin{array}{l}\text { Smokers } \\
(\mathbf{n}=\mathbf{2 1 2})\end{array}$ & $\begin{array}{c}\text { Non-smokers } \\
(\mathbf{n}=\mathbf{1 5 9})\end{array}$ \\
\hline Age (years) & $71.9(8.0) \dagger$ & $69.2(8.0)$ & $74.7(3.7)$ \\
Sex (M/F) & $152 / 32$ & $182 / 30$ & $129 / 30$ \\
Smoking (pack-years) & $36.6(11.5) \$$ & $33.2(12.8)$ & 0 \\
FEV $1 \%$ pred) & $47.2(16.3) \S$ & $103.2(13.7)$ & $96.6(15.4)$ \\
FEV $_{1} /$ FVC & $45.8(8.6)^{\uparrow}$ & $79.2(5.9)$ & $77.5(7.2)$ \\
Serum VEGF $(\mathrm{pg} / \mathrm{ml})$ & $282.7(13.3)^{* *}$ & $318.4(19.6)$ & $296.8(26.1)$ \\
Serum PIGF $(\mathrm{pg} / \mathrm{ml})$ & $27.1(7.4)^{*}$ & $12.3(5.1)$ & $10.8(6.3)$
\end{tabular}

All values are shown as mean (SE).
COPD, chronic obstructive pulmonary disease; $\mathrm{FEV}_{1}$, forced expiratory volume in $1 \mathrm{~s}$; FVC, forced vital capacity; VEGF, vascular
endothelial growth factor; PIGF, placenta growth factor.
${ }^{*} p=0.005 ; \dagger p=0.33 ; \mathrm{tp}=0.12 ; \xi p<0.001 ; \uparrow p<0.001 ;{ }^{* *} p=0.35$ (F test between the three groups).

COPD was diagnosed on the basis of history, chest radiographic findings, physical examination and spirometric data, according to the American Thoracic Society guidelines. ${ }^{11}$ Inclusion criteria for COPD included: chronic airway symptoms and signs such as coughing, breathlessness, wheezing and chronic airway obstruction, which was defined as (1) ratio of forced expiratory volume in $1 \mathrm{~s}$ to forced vital capacity $\left(\mathrm{FEV}_{1} / \mathrm{FVC}\right)<70 \%$; (2) $\mathrm{FEV}_{1}$ $<80 \%$ of the predicted value via spirometric data; and (3) $\mathrm{FEV}_{1}$ reversibility after inhalation of $200 \mu \mathrm{g}$ salbutamol of $<12 \%$ of prebronchodilator $\mathrm{FEV}_{1}$. Subjects were excluded if they had a history of asthma (reversibility of airflow obstruction) or malignant lung disease.

The control group included 212 asymptomatic smokers or exsmokers (182 men and 30 women) with a smoking history of at least 10 pack-years without clinical or laboratory evidence of COPD and 159 never smokers (129 men and 30 women). All were subjects who visited the hospital for a health examination. All control subjects had normal pulmonary function ( $\mathrm{FEV}_{1} / \mathrm{FVC}$ $>70 \%$ and $\mathrm{FEV}_{1}>80 \%$ of the predicted value) and no other comorbidities.

Peripheral blood was collected from patients with COPD and controls in heparinised syringes and centrifuged within 15 min of collection. The plasma was kept at $-70^{\circ} \mathrm{C}$ until analysis by a technician who was blinded to the condition of the patients.

\section{Study population 2}

Analysis of VEGF and PIGF levels in BAL fluid was also performed in 20 patients with COPD and 18 controls (study population 2). Haemoptysis was the indication for bronchoscopy in most patients and controls, and BAL was performed if there was no evidence of bleeding or bronchial lesions. Patients with asthma, malignant lung disease or infectious processes in the airway were excluded.

\section{Bronchoalveolar lavage}

Bronchoscopy was performed according to the standard protocol. After topical anaesthesia with $2 \%$ xylocaine, BAL was performed with four $50 \mathrm{ml}$ aliquots of phosphate buffered saline instilled into the right middle lobe. The investigator made sure that no blood component was found after normal saline instillation and suction. The BAL fluid was aspirated into a siliconised glass bottle and stored on ice until processing. The chilled BAL fluid was strained through a single layer of coarse gauze to remove clumps of mucus and then spun at $400 \mathrm{~g}$ for 5 min to recover cells. If red blood cells were found the samples were discarded. BAL fluid supernatant was collected and stored at $-80^{\circ} \mathrm{C}$ until analysis.

\section{Measurement of VEGF, PIGF and cytokines in serum and BAL fluid}

Serum and BAL fluid levels of VEGF and PIGF were assayed by a standardised sandwich enzyme-linked immunosorbent assay (ELISA) method (R\&D Systems, Minneapolis, MN, USA) in duplicate according to the manufacturer's protocol.

We calculated the concentrations of VEGF, PIGF and proinflammatory cytokines (interleukin-1 $\beta$ (IL-1 $\beta$ ), tumour necrosis factor (TNF)- $\alpha$, transforming growth factor (TGF)- $\beta$, epidermal growth factor (EGF) and IL-8) divided by the albumin concentration $(\mathrm{pg} / \mathrm{ml})$ in BAL fluid. The concentration of albumin in the BAL fluid was assayed by the bromocresol green method (Seiken, Tokyo, Japan). The amounts of VEGF, PIGF and the cytokines in the BAL fluid were measured using an ELISA assay (R\&D Systems).

\section{Bronchial epithelial cell line}

S-cell (ATCC number CRL-9609) human bronchial epithelial cells were grown in F12 nutrient mixture (GIBCO, Invitrogen Corporation) with $0.5 \mathrm{ng} / \mathrm{ml}$ recombinant epidermal growth factor, $500 \mathrm{ng} / \mathrm{ml}$ hydrocortisone, $0.005 \mathrm{mg} / \mathrm{ml}$ insulin, $0.035 \mathrm{mg} / \mathrm{ml}$ bovine pituitary extract, $500 \mathrm{nM}$ ethanolamine, $500 \mathrm{nM}$ phosphoethanolamine, $0.01 \mathrm{mg} / \mathrm{ml}$ transferrin, $6.5 \mathrm{ng} /$

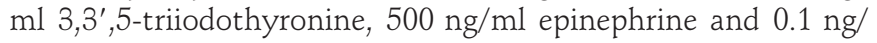
$\mathrm{ml}$ retinoic acid. Cells were grown to confluence in medium supplemented with $10 \%$ fetal calf serum which was then replaced with serum-free medium for experiments.

\section{Cell culture experiments}

The effects of IL- $1 \beta$, TNF- $\alpha$, TGF- $\beta$, EGF and IL-8 (all purchased from R\&D Systems) on the expression of VEGF and PIGF in lung epithelial cells were tested. These cytokines were selected because they are proinflammatory cytokines and play important roles in the pathogenesis of COPD. ${ }^{12}$ Final concentrations were $10 \mathrm{ng} / \mathrm{ml}$ for each cytokine.

The effect of PIGF on VEGF in lung epithelial cells was investigated by daily treatment with various agents including PlGF $(50 \mathrm{pg} / \mathrm{ml})$, TNF- $\alpha(200 \mathrm{pg} / \mathrm{ml})$ and IL-8 $(200 \mathrm{pg} / \mathrm{ml})$, individually or concomitantly. The concentrations of cytokines were chosen because they were the mean levels of each cytokine in BAL fluid samples from patients with COPD.

The cells were treated for 14 days and VEGF expression in the conditioned media was evaluated. The conditioned media were subjected to the ELISA assay according to the manufacturer's guidelines. Proteins $(75 \mu \mathrm{g})$ extracted from treated cells were subject to electrophoresis on 10\% gradient Bio-Tris gels (Novex, San Diego, California, USA) and transferred to PolyScreen 


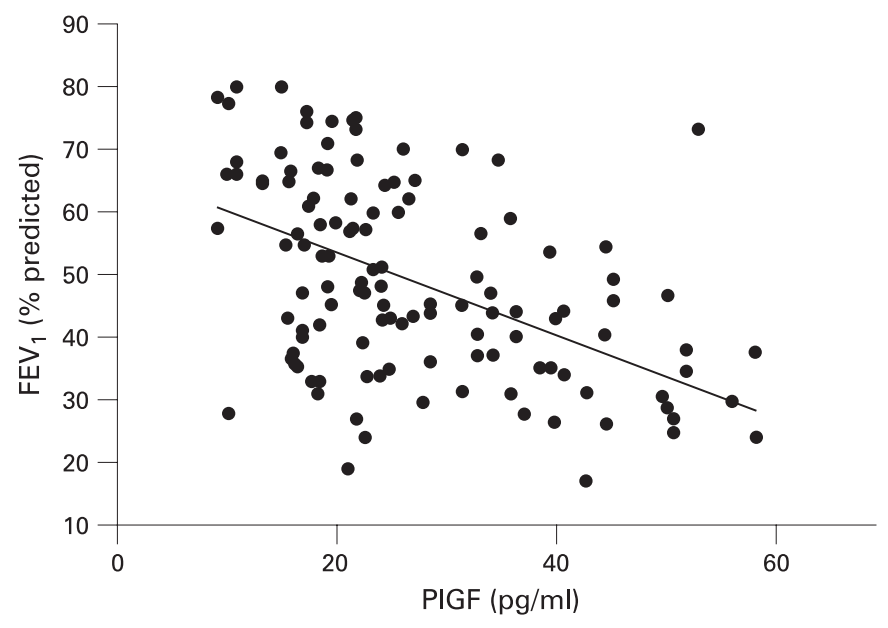

Figure 1 Correlation between the serum concentration of placenta growth factor (PIGF) and forced expiratory volume in $1 \mathrm{~s}\left(\mathrm{FEV}_{1}\right)$ percentage predicted in patients with COPD $(r=-0.59, p=0.002)$. The serum levels of PIGF were inversely correlated with $\mathrm{FEV}_{1}$.

polyvinylidine difluoride transfer membranes (Millipore Corp, Bedford, Massachusetts, USA). The primary antibodies (1:1000 dilution) were anti-human VEGF $_{165}$ and anti-human actin (R\&D Systems). The secondary antibody was anti-goat horseradish peroxidase-conjugated antibody (BioSource International, Camarillo, California, USA). VEGF 165 was selected as being a pivotal form of the VEGF family and essential to VEGF function.

The percentage of dead cells was determined by trypan blue exclusion. Spontaneous uptake of trypan blue as a vital dye by cells was then assessed by light microscopy. Apoptosis analysis for S-cells was performed using the HTS caspase-3 assay (Oncogene Research Products, San Diego, California, USA) according to the manufacturer's protocol at different time points.

In a set of cells treated concomitantly with PIGF, TNF- $\alpha$ and IL-8, a VEGF receptor inhibitor, CBO-P11 (Calbiochem, San Diego, California, USA), was added in a concentration of $1 \mu \mathrm{M}$ at which the binding of VEGF 165 to VEGFR1 $\left(\mathrm{IC}_{50}=700 \mathrm{nM}\right.$ )
Table 2 Age, sex, smoking and pulmonary function data in patients with COPD and controls (study population 2)

\begin{tabular}{lll}
\hline Variables & $\begin{array}{l}\text { COPD } \\
\text { (n= 20) }\end{array}$ & $\begin{array}{l}\text { Controls } \\
(\mathbf{n}=\mathbf{1 8})\end{array}$ \\
\hline Age (years) & $51.4(12.8) \dagger$ & $45.6(9.5)$ \\
Sex (M/F) & $18 / 2$ & $8 / 10$ \\
Smoking (pack-years) & $18.3(11.9) \dagger$ & $15.6(10.2)$ \\
FEV $_{1}$ (\% pred) & $73.4(7.8) \S$ & $94.8(10.1)$ \\
FEV $_{1} /$ FVC & $63.1(6.4)$ & $83.5(4.6)$ \\
Albumin in BAL fluid (mg/ml) & $0.13(0.03)^{* *}$ & $0.11(0.06)$ \\
Serum VEGF (pg/ml) & $298.7(37.6) \dagger \dagger$ & $321.9(30.3)$ \\
Serum PIGF (pg/ml) & $22.4(9.7)^{*}$ & $13.2(7.8)$ \\
\hline
\end{tabular}

All values are shown as mean (SE).

$\mathrm{FEV}_{1}$, forced expiratory volume in $1 \mathrm{~s}$; FVC, forced vital capacity; BAL, bronchoalveolar lavage; VEGF, vascular endothelial growth factor; PIGF, placenta growth factor. ${ }^{*} \mathrm{p}<0.05 ; \dagger \mathrm{p}=0.41 ; \mathrm{t} \mathrm{p}=0.38 ; \xi \mathrm{p}=0.007 ; \boldsymbol{\top} \mathrm{p}=0.006 ;{ }^{*} \mathrm{p}=0.57 ; \dagger \mathrm{p}=0.47$.

was blocked but the binding to VEGFR2 $\left(\mathrm{IC}_{50}=1.3 \mu \mathrm{M}\right)$ was preserved..$^{13}$ The influence of CBO-P11 on VEGF expression and $\mathrm{S}$-cell apoptosis was examined. The dose-response of CBO-P11 was also tested with concentrations from $10 \mathrm{nM}$ to $1 \mu \mathrm{M}$ on day 14 of concomitant treatment with PIGF and cytokines to determine the $\mathrm{EC}_{50}$ for $\mathrm{CBO}-\mathrm{P} 11$ in preventing VEGF suppression and apoptosis.

\section{Data analysis}

All the data are expressed as mean (SE) for normally distributed data. Statistical analysis was performed using SPSS 9.0 for Windows (SPSS Inc, Chicago, Illinois, USA) and analysed using post hoc testing (Scheffe test) for multiple comparisons and linear regression. A p value of $<0.05$ was considered statistically significant.

\section{RESULTS}

Age, sex, smoking history and pulmonary function data of patients with COPD and control subjects (study population 1) are summarised in table 1 . There were no significant differences in age or smoking history between patients with COPD and controls.

There was no significant difference in the mean (SE) serum levels of VEGF between patients with COPD and controls (COPD: 282.7 (13.3) pg/ml; smokers: 318.4 (19.6) pg/ml;
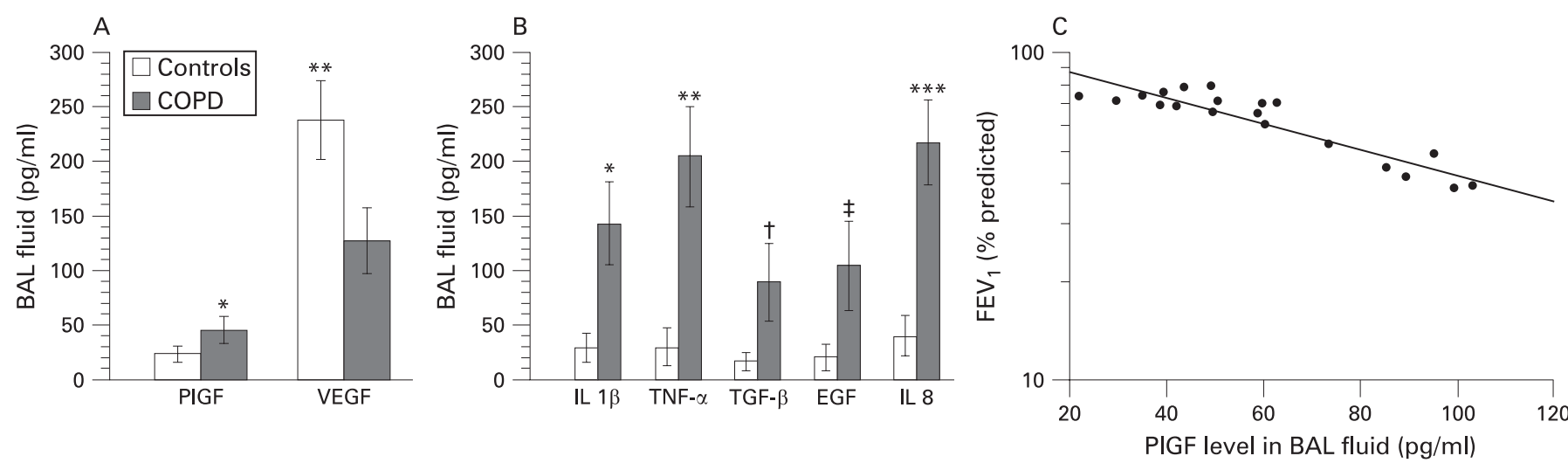

Figure 2 (A) Concentrations of vascular endothelial growth factor (VEGF) and placenta growth factor (PIGF) in bronchoalveolar lavage (BAL) fluid in patients with chronic obstructive pulmonary disease (COPD) and controls $\left({ }^{*} p=0.005,{ }^{*} p=0.002\right)$. Error bars are presented as standard errors. (B) Concentrations of cytokines in BAL fluid in patients with COPD and controls. IL-1 $\beta$, interleukin-1 $\beta$; TNF- $\alpha$, tumour necrosis factor- $\alpha$; TGF- $\beta$, transforming growth factor- $\beta$; EGF, epidermal growth factor; IL-8, interleukin-8. $\left({ }^{*} p=0.003 ;{ }^{* *} p=0.001 ; \dagger p=0.005 ; \ddagger p=0.003 ;{ }^{* * *} p=0.001\right)$. Error bars are presented as standard errors. The coefficients of variation within and between batches were 0.17 and 0.24 , respectively. (C) Relationship between PIGF levels in BAL fluid and forced expiratory volume in $1 \mathrm{~s}\left(\mathrm{FEV}_{1}\right)$ percentage predicted in patients with $\mathrm{COPD}(r=-0.51, p=0.001)$. Higher PIGF levels in BAL fluid correlated with worse lung function. 

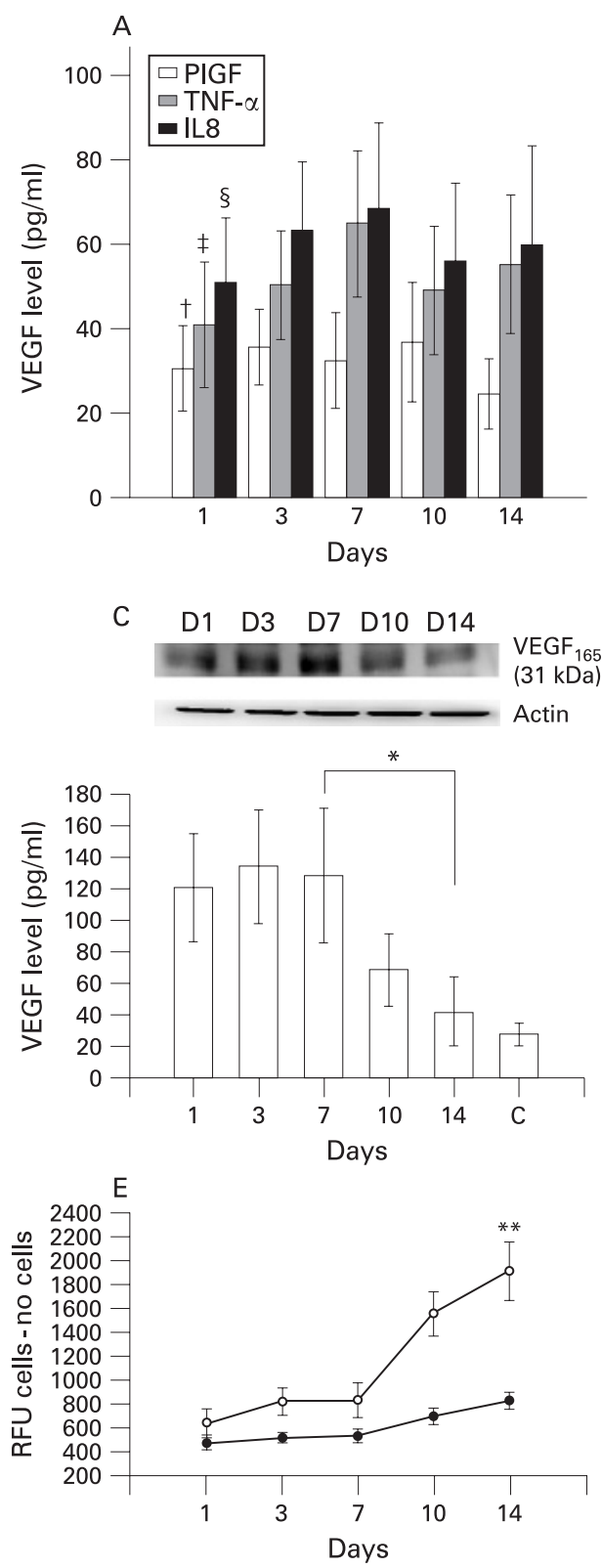

B
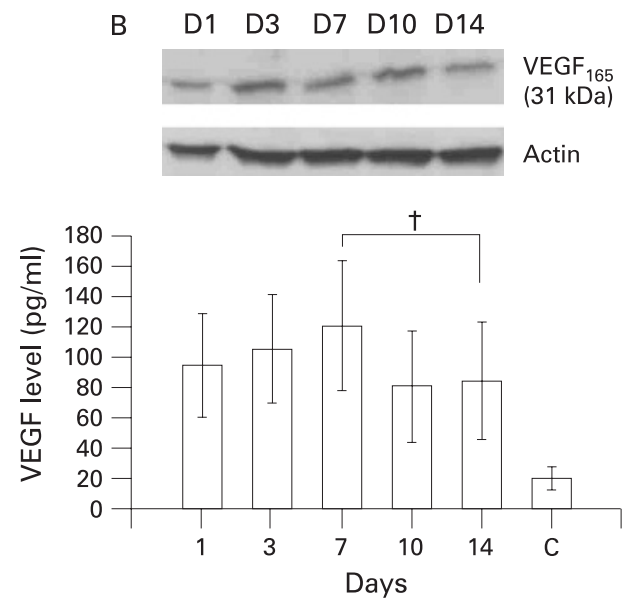

D

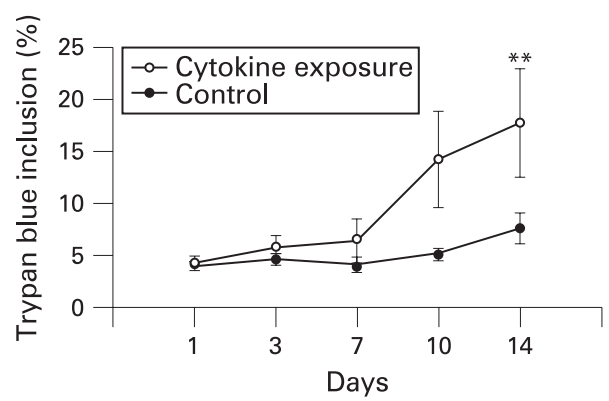

Figure 3 (A) Effect of persistent stimulation with exogenous PIGF, TNF- $\alpha$ or IL-8 on VEGF expression in S-cells. There was no significant difference in VEGF levels in individual exposures from day 1 to day $14(\dagger p=0.24, \$ p=0.31, \S p=0.16$ from day 1 to day 14 individually. Error bars are presented as standard deviations. (B) Effect of persistent stimulation with a combination of TNF- $\alpha$ and IL-8 on VEGF expression in S-cells. Western blotting and ELISA analysis show VEGF expression from day 1 to day 14 . There was no statistical difference during this period $(\dagger p=0.43) ; C$, control at day 14 . Error bars are presented as standard deviations. (C) Effect of persistent stimulation with a combination of PIGF, TNF- $\alpha$ and IL-8 on VEGF suppression in S-cells. Western blotting and ELISA analysis show VEGF expression from day 1 to day 14 . There was a statistically significant difference from day 7 to day 14 with gradual downregulation of VEGF expression $\left({ }^{*} \mathrm{p}<0.05\right) ; \mathrm{C}$, control at day 14. Error bars are presented as standard deviations. (D) Percentage S-cell viability following stimulation with a combination of PIGF, TNF- $\alpha$ and IL- 8 measured by trypan blue exclusion. The percentage of cell deaths was significantly increased after 14 days of cytokine exposure ( ${ }^{* *} p<0.05$ vs day 7). Error bars are presented as standard deviations. (E) Caspase- 3 activity assay in S-cells after stimulation with a combination of PIGF, TNF- $\alpha$ and IL-8. The signal was analysed after subtracting the appropriate number of cells/buffer controls. Caspase-3 activity gradually increased after 14 days of exposure $\left({ }^{* *} p<0.01\right.$ vs day 7). Error bars are presented as standard deviations. VEGF, vascular endothelial growth factor; PIGF, placenta growth factor; TNF- $\alpha$, tumour necrosis factor- $\alpha$; IL-8, interleukin-8; RFU, relative signal.

non-smoker controls: $296.8(26.1) \mathrm{pg} / \mathrm{ml}, \quad \mathrm{p}=0.35, \quad \mathrm{~F}$ test between the three samples). However, the serum levels of PIGF were significantly higher in patients with COPD $(27.1(7.4) \mathrm{pg} / \mathrm{ml}$ than in the controls (smokers: $12.3(5.1) \mathrm{pg} / \mathrm{ml}$; non-smoker controls: 10.8 (6.3) pg/ml, $\mathrm{p}=0.005$ ). Moreover, the serum levels of PIGF correlated inversely with the value of $\mathrm{FEV}_{1}$ in patients with COPD ( $r=-0.59, p=0.002$; fig 1). Patients with higher PIGF levels tended to have lower $\mathrm{FEV}_{1}$ values.
The characteristics of the 38 subjects (study population 2) receiving bronchoscopic examination and BAL are presented in table 2. The serum levels of PIGF were still significantly higher in patients with COPD $(22.4(9.7) \mathrm{pg} / \mathrm{ml}$ than in controls (13.2 (7.8) $\mathrm{pg} / \mathrm{ml}, \mathrm{p}<0.05)$, but the serum concentrations of VEGF were similar in the two groups. The concentrations of VEGF and PIGF in the BAL fluid of patients with COPD and controls are shown in fig 2A. The levels of VEGF were significantly lower 
A
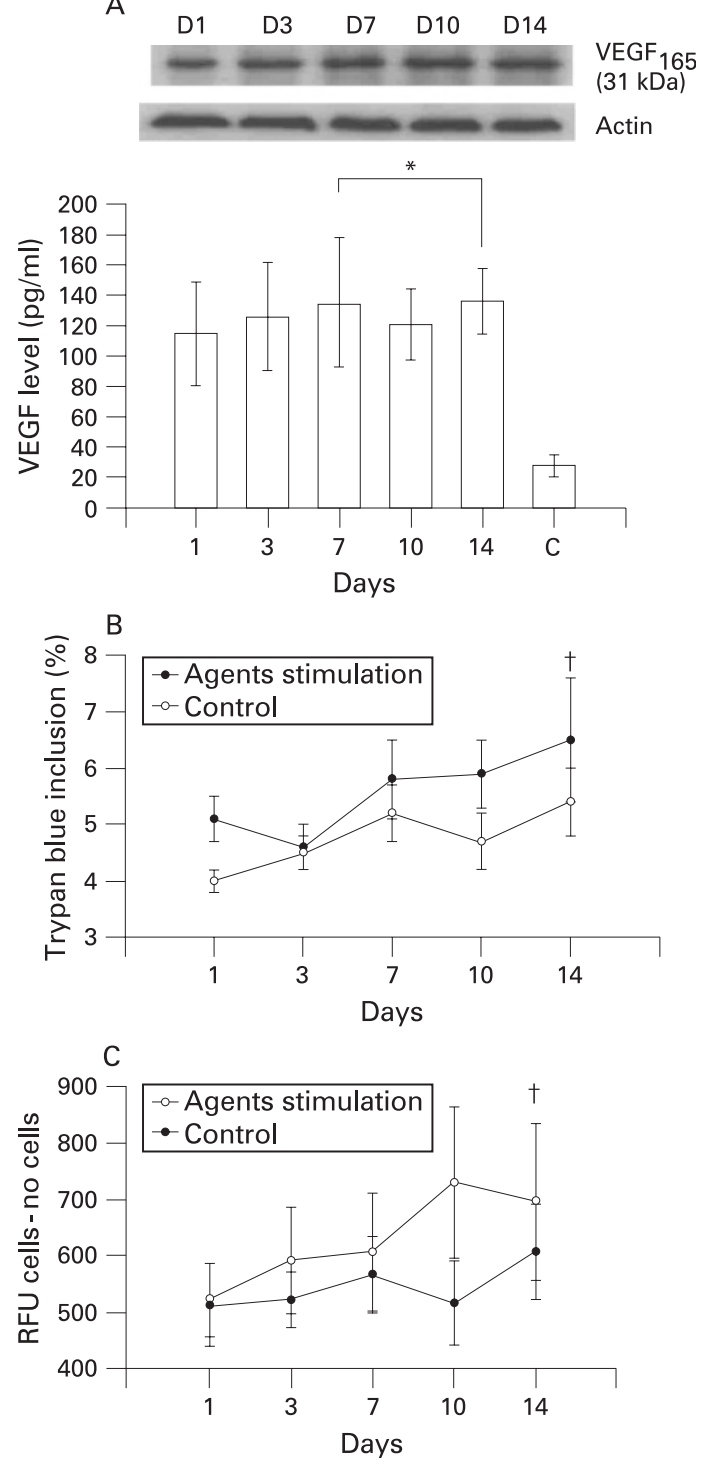

Figure 4 (A) Effect of persistent stimulation with a combination of PIGF, TNF- $\alpha$, IL-8 and CBO-P11 $1 \mu \mathrm{M} / \mathrm{I}$ on VEGF expression in S-cells. Western blotting and ELISA analysis show VEGF expression from day 1 to 14 . There was no statistically significant difference during this period ( $\left.{ }^{*} p=0.52\right) ; C$, control at day 14. Error bars are presented as standard deviations. (B) Percentage S-cell viability following stimulation with a combination of PIGF, TNF- $\alpha$, IL- 8 and CBO-P1 1 measured by trypan blue exclusion. The percentage of cell deaths was not significantly increased after 14 days of exposure ( $\dagger p=0.61$ vs day 7). Error bars are presented as standard deviations. (C) Caspase-3 activity assay for S-cells after stimulation with a combination of PIGF, TNF- $\alpha$, IL-8 and CBO-P11. The signal was analysed after subtracting the appropriate number of cells/buffer controls. Caspase-3 activity did not increase after 14 days of exposure ( $\dagger p=0.37$ vs day 7 ). Error bars are presented as standard deviations. VEGF, vascular endothelial growth factor; PIGF, placenta growth factor; TNF- $\alpha$, tumour necrosis factor$\alpha$; IL-8, interleukin-8; RFU, relative signal.

in patients with COPD than in normal subjects (COPD 127.5 (30.1) $\mathrm{pg} / \mathrm{ml}$ vs controls 237.8 (36.1) $\mathrm{pg} / \mathrm{ml}, \quad \mathrm{p}=0.002)$. However, the concentrations of PIGF in patients with COPD were higher than those of controls (COPD 45.7 (12.3) $\mathrm{pg} / \mathrm{ml}$ vs controls $23.9(7.6) \mathrm{pg} / \mathrm{ml}, \mathrm{p}=0.005$; table 2). The levels of proinflammatory cytokines in BAL fluid from patients with COPD (IL-1 $\beta$ : 143.4 (37.9), TNF- $\alpha$ : 205.7 (46.1), TGF- $\beta$ : 89.5 (35.1), EGF:104.3 (40.7) and IL-8: $216.8(38.9) \mathrm{pg} / \mathrm{ml}$ ) were also significantly higher than those from controls (IL-1 $\beta$ : 29.8 (13.6),
TNF- $\alpha$ : 30.5 (17.2), TGF- $\beta$ : 17.4 (8.5), EGF: 21.3 (11.6) and IL-8: 40.2 (18.3) pg/ml; fig 2B). Moreover, higher BAL fluid levels of PIGF were significantly correlated with worse lung function represented by $\mathrm{FEV}_{1}(\mathrm{r}=-0.51, \mathrm{p}=0.001$; fig $2 \mathrm{C})$. The levels of VEGF in BAL fluid did not correlate with $\mathrm{FEV}_{1}(\mathrm{r}=0.12$, $\mathrm{p}=0.51$.

\section{Effect of cytokines on PIGF and VEGF expression}

After exposure to proinflammatory cytokines (IL-1 $\beta$, TNF- $\alpha$, TGF- $\beta$ and EGF), the expression of PIGF by S-cells increased with time. PIGF protein levels were increased $2-3$-fold at $6 \mathrm{~h}$ and by 4-5-fold at $18 \mathrm{~h}$. The levels of VEGF were also significantly increased after stimulation with the same cytokines. VEGF expression increased continuously from 6 to $18 \mathrm{~h}$ of culture with IL-1 $\beta$, TNF- $\alpha$ and IL-8. However, VEGF levels cultured with TGF- $\beta$ and EGF fell at $18 \mathrm{~h}$.

\section{Effect of persistent stimulation with PIGF, TNF- $\alpha$ and IL-8 on VEGF expression}

The expression of VEGF after 14 days of treatment with PIGF, TNF- $\alpha$ or IL-8 using concentrations close to those in the BAL fluid of patients with COPD (PIGF $50 \mathrm{pg} / \mathrm{ml}$, TNF- $\alpha 200 \mathrm{pg} / \mathrm{ml}$ and IL-8 $200 \mathrm{pg} / \mathrm{ml}$ ) is shown in fig 3A. With TNF- $\alpha$ or IL-8 stimulation alone, the expression of VEGF gradually increased during the initial 7 days and then decreased after 10-14 days of treatment. The same finding was noted after concomitant treatment with TNF- $\alpha(200 \mathrm{pg} / \mathrm{ml})$ and IL-8 $(200 \mathrm{pg} / \mathrm{ml})$ for 10 days (fig $3 \mathrm{~B}$ ). After 10 days exposure to $50 \mathrm{pg} / \mathrm{ml}$ PIGF alone the level of VEGF decreased (fig $3 \mathrm{~A}$ ), but the expression of VEGF was significantly reduced after 10 days of concomitant treatment with PIGF $(50 \mathrm{pg} / \mathrm{ml})$, TNF- $\alpha(200 \mathrm{pg} / \mathrm{ml})$ and IL-8 $(200 \mathrm{pg} / \mathrm{ml})$ (fig 3C). A cell viability test showed a significant increase in the percentage of dead cells after cytokine exposure for 14 days (fig 3D). Apoptosis analysis with the caspase-3 activity assay showed a considerable increase in apoptotic cells during the 14 days of stimulation (fig $3 \mathrm{E}$ ). The addition of VEGFR inhibitor (CBO-P11) in a concentration that mainly blocked VEGFR1 binding throughout the 14-day experimental period to the mixture of TNF- $\alpha$, IL-8 and PIGF avoided the suppression of VEGF expression (fig 4A), maintained S-cell viability (fig 4B) and prevented apoptosis (fig 4C). CBO-P11 prevented the suppression of VEGF expression in a dosedependent manner (fig 5A) with an $\mathrm{EC}_{50}$ of $415 \mathrm{nM}$ (fig 5B). The caspase-3 activity was also ameliorated with increasing doses of CBO-P11 (fig 5C).

\section{DISCUSSION}

In this study we have demonstrated the potential mechanism of PIGF in the pathogenesis of COPD. The expression of PIGF increases as a response of airway epithelial cells to proinflammatory cytokines. The sustained stimuli of cytokines and PIGF subsequently reduces VEGF expression and promotes the apoptosis of airway epithelial cells through VEGFR. The apoptosis of epithelial cells is considered essential for the pathogenesis of pulmonary emphysema.

This study has several limitations. First, the numbers of men and women were not balanced and a relatively small population was recruited, especially in study population 2 in which there were few patients with severe COPD. In Taiwan about $90 \%$ of patients with COPD and chronic smokers are men. Furthermore, it is difficult to perform bronchoscopy in patients with severe obstructive lung function because of the invasive nature of the procedure and poor baseline status. Second, BAL 

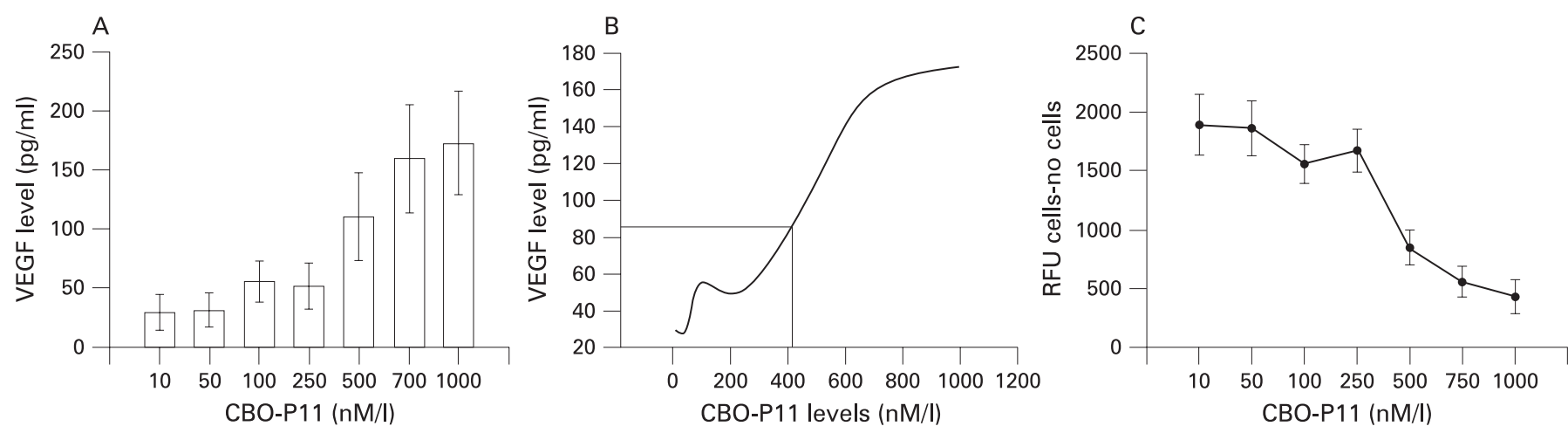

Figure 5 (A) S-cells were cultured with fixed concentrations of PIGF, TNF- $\alpha$, IL-8 and the indicated concentrations of CBO-P11 for 14 days. The expression of VEGF in conditioned medium was measured. Error bars are presented as standard deviations of triplicate. (B) Dose-response curve of CBO-P11 showing an EC 50 of $415 \mathrm{nM} / \mathrm{I}$. (C) Caspase-3 activity assay of S-cells cultured with fixed concentrations of PIGF, TNF- $\alpha$, IL-8 and the indicated concentrations of CBO-P11 for 14 days. Error bars are presented as standard deviations. VEGF, vascular endothelial growth factor; PIGF, placenta growth factor; TNF- $\alpha$, tumour necrosis factor- $\alpha$; IL-8, interleukin-8; RFU, relative signal.

was performed only after definite exclusion of gross bleeding or blood clot and the samples were discarded if they were obviously haemorrhagic. However, we still could not be sure that there were no microscopic red blood cells which would affect the measurement of PIGF expression. Third, the S-cell line comprised transformed cells from primary airway epithelial cells; it is unknown whether the expression of VEGF and PIGF in S-cells could represent primary cells.

Previous studies have focused on the downregulation of VEGF and VEGFR2 in emphysematous lung tissue. ${ }^{4}$ In this study we have confirmed the reduced expression of VEGF in patients with COPD by measuring the levels of VEGF in BAL fluid. On the other hand, the serum and BAL fluid levels of PIGF (a VEGF homologue) increased in patients with COPD compared with smokers with normal lung function.

PIGF expression increases significantly in early gestation, peaks at around 26-30 weeks and decreases as term approaches. ${ }^{14}$ The biological function of PIGF after gestation and in adulthood remains unclear. The cell origins of PIGF are also unknown. Although there is evidence that synergism between VEGF and PIGF contributes to angiogenesis and plasma extravasation in pathological conditions such as in ischaemia or inflammation, ${ }^{15}$ we have shown that bronchial epithelial cells can express PIGF and the levels of PIGF are increased in patients with COPD.

We found that the serum concentrations of PIGF in patients with COPD were inversely correlated with $\mathrm{FEV}_{1}$, and higher BAL fluid levels of PIGF were seen in patients with worse airflow limitation. The increased levels of PIGF in patients with COPD may result from the stimulation of proinflammatory mediators, as we found an increase in proinflammatory cytokines in BAL fluid of patients with COPD and a bronchial epithelial cell line (S-cells) was shown to express PIGF after exposure to a variety of proinflammatory cytokines. The relationship between serum or BAL fluid levels of PIGF and lung function, even if statistically significant, does not necessarily imply a cause and effect association.

Tsao et $a l^{10}$ have previously shown that PlGF transgenic mice develop pathology similar to human pulmonary emphysema. Our study is the first to investigate the potential role of PIGF in the pathogenesis of COPD in humans. Based on the findings of our work, we propose the following hypothesis to explain the possible role of increased levels of PIGF in the pathogenesis of COPD. The expression of PIGF is increased secondary to the stimuli of various inflammatory mediators participating in the pathogenesis of COPD, and the increase in PlGF-acting in combination with the inflammatory mediators-leads to the death of airway epithelial and endothelial cells. Tsao et al showed that PIGF inhibits the proliferation of MLE-15 cells (a mouse pulmonary type II epithelial cell line) in a dosedependent manner and significantly promotes the death of these cells. ${ }^{10}$ In our study, persistent treatment of PIGF, combined with TNF- $\alpha$ and IL-8, induced downregulation of VEGF in the human bronchial epithelial cells most likely through reducing the number of viable cells and increasing cell apoptosis. Since the concentrations of PIGF, TNF- $\alpha$ and IL-8 used in cell cultures were close to those measured in BAL fluid in patients with COPD, our finding could be pathologically relevant. We have shown in vitro that the chronic stimulation of epithelial cells with PIGF and other cytokines induces cell death and apoptosis, which is similar to the exposure to chronic irritants associated with lung parenchymal damage in vivo. We have also shown that this phenomenon can be abolished by a VEGFR inhibitor in a concentration mainly blocking VEGFR1. Since VEGFR1 is the receptor of PIGF, the latter is then considered to play an important role in the pathogenesis of COPD. Based on the available evidence, increased PIGF levels can be acknowledged as one factor-acting in combination with multiple cytokines-in the multifactorial pathogenesis of COPD.

We are aware that only $10-15 \%$ of smokers develop COPD. In our study, smokers with normal lung function had serum PIGF levels close to those in non-smokers despite consuming an equal amount of cigarettes to smokers with COPD. The non-COPD smokers also had fewer proinflammatory cytokines in the BAL fluid than smokers with COPD. Host factors such as genetic polymorphisms of susceptible genes may play an important role in the development of COPD. Subjects carrying genetic variants of increased function of detoxifying enzymes or a reduced response of inflammatory cytokines may generate a lower inflammatory response to cigarette smoke ${ }^{16} 17$ so, based on our hypothesis, they have lower PIGF expression and less smokingrelated damage to the lung parenchyma. It is also possible that each individual may have different capabilities for expressing PIGF under inflammatory stress, but further investigations are needed to confirm this notion.

VEGF expression in the serum did not change, unlike the expression of VEGF in the BAL fluid. Since the serum levels of 
VEGF or PIGF may be affected by other organs or conditions such as tissue hypoxaemia or inflammation, the expression of both factors in BAL fluid should represent more accurately the changes in lung parenchyma and reflect the real pathological mechanisms of lung diseases.

COPD is traditionally classified into chronic bronchitis and emphysema. The pathogenesis and clinical manifestations of these two subtypes may be somehow different. However, few biological markers can clearly differentiate one from the other. Previous investigators have reported increased levels of VEGF in induced sputum from patients with chronic bronchitis and decreased amounts in patients with emphysema. ${ }^{18}$ As far as we know, cigarette smoke reduces VEGF and VEGF receptor expression and signalling, resulting in pulmonary endothelial cell death followed by progressive disappearance of the alveolar septum. ${ }^{19}$ Whether downregulation of VEGF resulting from overexpression of PlGF contributes to the pathogenesis of pulmonary emphysema or whether overexpression of VEGF leading to airway and vessel remodelling contributes to chronic bronchitis still needs to be elucidated. Previous investigators have reported contradictory findings regarding VEGF expression in COPD. Kranenberg et $a l^{20}$ demonstrated enhanced bronchial expression of VEGF and its receptors in patients with COPD. However, Kanazawa and Yoshikawa ${ }^{21}$ showed that sputum levels of VEGF decreased with the severity of COPD, a finding similar to ours. These authors later reported an increase in sputum VEGF levels in patients with "bronchitis-type" COPD. ${ }^{22}$ The above findings reflect the nature of COPD as a disease spectrum with variable phenotypes-emphysema, chronic bronchitis, or mostly mixed; the role of angiogenesis should be different in each phenotype. Further investigations are required to recruit more patients with COPD in order to focus on specific pathological changes or phenotypes to clarify the role of these two angiogenic growth factors in COPD.

In summary, our results suggest that the levels of PIGF are increased in patients with COPD, which might contribute to the pathogenesis of COPD. Subjects with higher PIGF levels in serum and BAL fluid had worse lung function. This study also shows that human bronchial epithelial cells can express PIGF, and continuous stimulation of PlGF and proinflammatory cytokines can suppress VEGF. Persistent PIGF expression might have adverse effects on lung parenchyma by downregulating angiogenesis. The mechanisms behind the observed detrimental effects of PIGF remain to be clarified.

\section{Competing interests: None.}

Ethics approval: Ethical approval was obtained from the hospital and informed consent was obtained from all study subjects and controls.

\section{REFERENCES}

1. Hunninghake GW, Crystal RG. Cigarette smoking and lung destruction Accumulation of neutrophils in the lung of cigarette smokers. Am Rev Respir Dis 1983;128:833-8.

2. Kanazawa $\mathbf{H}$, Kurihara N, Hirata $\mathrm{K}$, et al. The role of free radicals and neutrophil elastase in development of pulmonary emphysema. Intern Med 1992;31:857-60.

3. Liebow AA. Pulmonary emphysema with special reference to vascular change. Am Rev Respir Dis 1959;80:67-93.

4. Kasahara Y, Tuder RM, Cool CD, et al. Endothelial cell death and decreased expression of vascular endothelial growth factor and vascular endothelial growth factor receptor 2 in emphysema. Am J Respir Crit Care Med 2001;163:737-44.

5. Marwick JA, Stevenson CS, Giddings J, et al. Cigarette smoke disrupts VEGF165VEGFR-2 receptor signaling complex in rat lungs and patients with COPD: morphological impact of VEGFR-2 inhibition. Am J Physiol Lung Cell Mol Physiol 2006;290:L897-908.

6. Maglione D, Guerriero V, Viglietto G, et al. Isolation of a human placenta cDNA coding for a protein related to the vascular permeability factor. Proc Natl Acad Sci USA 1991;88:9267-71.

7. Ziche M, Maglione D, Ribatti D, et al. Placenta growth factor-1 is chemotactic, mitogenic, and angiogenic. Lab Invest 1997;76:517-31.

8. Park JE, Chen HH, Winer J, et al. Placenta growth factor. Potentiation of vascular endothelial growth factor bioactivity, in vitro and in vivo, and high affinity binding to Flt-1 but not to Flk-1/KDR. J Biol Chem 1994;269:25646-54.

9. DiPalma T, Tucci M, Russo G, et al. The placenta growth factor gene of the mouse. Mamm Genome 1996:7:6-12.

10. Tsao PN, Su YN, Li H, et al. Over-expression of placenta growth factor contributes to the pathogenesis of pulmonary emphysema. Am J Respir Crit Care Med 2004:169:505-11.

11. Celli ER, MacNeeW, ATS/ERS Task Force. Standards for the diagnosis and treatment of patients with COPD: a summary of the ATS/ERS position paper. Eur Respir J 2004;23:932-46.

12. Chung KF. Cytokines in chronic obstructive pulmonary disease. Eur Respir J 2001:18(Suppl 34):50-9s.

13. Zilberberg L, Shinkaruk S, Lequin 0 , et al. Structure and inhibitory effects on angiogenesis and tumor development of a new vascular endothelial growth inhibitor J Biol Chem 2003:278:35565-73.

14. Torry DS, Wang HS, Wang TH, et al. Preeclampsia is associated with reduced serum levels of placenta growth factor. Am J Obstet Gynecol 1998;179:1539-44.

15. Carmeliet P, Moons L, Luttun A, et al. Synergism between vascular endothelia growth factor and placental growth factor contributes to angiogenesis and plasma extravasation in pathological conditions. Nat Med 2001;7:575-83.

16. Hassett C, Aicher L, Sidhu JS, et al. Human microsomal epoxide hydrolase: genetic polymorphism and functional expression in vitro of amino acid variants. Hum $\mathrm{Mol}$ Genet 1994:3:421-8.

17. Pastorelli R, Guanci R, Panigalli T, et al. Impact of inherited polymorphisms in glutathione S-transferase M1, microsomal epoxide hydrolase, cytochrome P450 enzymes on DNA, and blood protein adducts of benzo(a)pyrene-diopepoxide. Cancer Epidemiol Biomarkers Prevent 1998;7:703-9.

18. Kanazawa H, Asai K, Hirate K, et al. Possible effects of vascular endothelial growth factor in the pathogenesis of chronic obstructive pulmonary disease. Am J Med 2003;114:354-8.

19. Tuder RM, Wood K, Tarasericiene L, et al. Cigarette smoke extract decreases the expression of vascular endothelial growth factor by cultured cells and triggers apoptosis of pulmonary endothelial cells. Chest 2000;117(Suppl):S241-2.

20. Kranenburg AR, de Boer Wl, Alagappan VK, et al. Enhanced bronchial expression of vascular endothelial growth factor and receptors (Flk-1 and Flt-1) in patients with chronic obstructive pulmonary disease. Thorax 2005;60:106-13.

21. Kanazawa $\mathbf{H}$, Yoshikawa J. Elevated oxidative stress and reciprocal reduction of vascular endothelial growth factor levels with severity of COPD. Chest 2005:128:3191-7.

22. Kanazawa H, Asai K, Nomura S. Vascular endothelial growth factor as a noninvasive marker of pulmonary vascular remodeling in patients with bronchitis-type of COPD. Respir Res 2007;8:8-22 